\begin{abstract}
This research reports the results of three independent studies which investigate the relationship between attraction and communicator style (the way a person communicates). Study 1 compores the communicator styles of "best liked" and "least liked" friends. The "best liked" friend's style differed significantly from that of the "least liked" friend, scoring higher on attraction. communicator image, open, attentive relaxed, and dramatic/animated. In study 2, four specific styles were studied in relation to attraction. The dominant/open style was seen by subjects as the most attractive; the not-dominant/not-relaxed style was seen as least attractive. In study 3, teachers rated students representing the four styles investigated in study 2 on a nine-item attraction measure entailing physical, personality. and liking dimensions. Again, the dominant/open style emerged as most attractive. The three studies provide strong evidence that communicator style is an important effect determinant of attraction.
\end{abstract}

\title{
COMMUNICATOR STYLE AS AN EFFECT DETERMINANT OF ATTRACTION
}

\author{
ROBERT W. NORTON \\ LOYD S. PETTEGREW \\ University of Michigan
}

Every person has a particular style of communicationthat is, the way one communicates. Since one's style of communication is a pervasive part of one's behavior, it is reasonable to expect that it affects how attractive a person appears to be. It can also be posited that some communicator styles are stronger covariates of attraction than other styles.

It is relatively easy to guess how attraction relates to styles of communication that are definitely visable. An ornery, contentious style tends to be offensive; a friendly, soft-spoken style tends to be appealing. When style-related components do not entail obviously positive or negative valences, it becomes increasingly difficult to anticipate which combination of communicator style variables best predict attraction.

No research in the literature directly investigates attraction as a function of communicator style. This paper reports

COMMUNICATION RESEARCH, Vol. 4 No. 3, July 1977

(C) 1977 Sage Publications. Inc. 
three successive studies which provide strong evidence that one's communicator style is an important effect determinant of attraction. The implications are of consequence. If the way one communicates influences the degree of attractiveness, then a multitude of interactive, social situations are affected, including therapeutic dynamics, teaching, intimate activity, persuasive processes, and problemsolving situations.

Attraction is investigated typically as a function of attitude similarity (Byren, 1969, 1971), economic similarity (Byrne, Clore, and Worchel, 1966), need similarity (lzard, 1961), and personality similarity (Griffitt, 1966, 1969). The researchers who attempt to make a statement about the relationship between communication and attraction often discover the obvious, highlight only physical manifestations, or tangentially relate communication variables.

Gullahorn (1952) and Newcomb (1961) suggest that opportunity to communicate (propinquity) correlates positively with interpersonal attraction. Dion, Berscheid, and Walster (1972) found that attractive persons are perceived as more sincere, more stable, and warmer. Mims, Harnett, and Nay (1975) tried to determine whether a given behavior of an individual or his physical appearance was a better determinant of attraction. However, the communication context (a debate) and the broad classification (nice versus obnoxious) limited the generalizability of their findings that the physical variable was the better predictor of attraction.

Lowe and Goldstein (1970), Holstein, Goldstein, and Bem (1971), and Mehrabian (1968, 1969) have researched the effects of individual expressive styles on attraction. Typical findings indicate that expressive cues can induce liking for a communicator. Most of these studies, however, isolate certain discrete variables while neglecting a more holistic consideration of communicator style.

Another area of research involving communication and attraction has focused on the vehicle of expression as the most important component in interaction. For example, 
Leginski and Izzett (1973) maintain that how one communicates is more influential than what is actually communicated with regard to social effectiveness and the success of the transaction. Williams (1975) points to the effect that various media have on style considerations. She found that the more immediate the medium (face-to-face interaction), the more positively the subjects were evaluated (Williams, 1975: 126-127). Less immediate media (telephone conversation and video taped communication) produced significantly less positive subject evaluations. The findings suggest that more immediate media permit a wider range of the person's style of communication to influence his evaluation by others.

In the therapeutic context, the communicator style of professional compared to the paraprofessional therapist was discovered to be a determinant of the client's attraction to them (Simonson and Bahr, 1974). The investigators concluded that the attractiveness of a therapist is not merely a function of content, but rather "involves the subject's knowledge of the therapist's style of interaction, which he might or might not like" (Simonson and Bahr, 1974: 362-363). In this study, style was defined in terms of self-disclosure and openness.

Finally, the personality literature provides implications regarding the relationship of communicator style to attraction. Byrne and Griffitt (1973) suggest that attraction is positively related to such personality dimensions as selfconcept, self-esteem, and dominance-submissiveness. Bales (1970), Bushard (1959), Ruesch (1957), Shapiro (1965), Watzlawick, Beavin, and Jackson (1967), and Weblin (1962) associate communicative behavior to the attractive personality.

It is clear from this substantive body of research that there is a strong empirical link between the way one communicates and how others regard one's attractiveness. This association, however, needs to be investigated in regard to a unified, more holistic construct of communicator style. 


\section{DEFINITION OF COMMUNICATOR STYLE}

In this research report, "communicator style" is broadly conceived to mean the way one verbally and paraverbally interacts to signal how literal meaning should be taken. interpreted, filtered, or understood. Communicator style is defined operationally in terms of nine independent variables that are dominant, open, dramatic, relaxed, contentious, animated, friendly, attentive, and impression-leaving. The dependent variable is communicator image, representing an evaluative consequent of the way one communicates, e.g., "I am a good communicator."

Norton (1974, 1977) has established communicator style as a multidimensional construct. Two versions of the communicator style measure (CSM) are avaiable. The longer version of the CSM is a 51-item, pencil-and-paper measure. Five items are summed for each of the nine independent variables; six items are summed to obtain an index score for the dependent variable. In the shorter version of the CSM, the five representative items for each independent variable are summarized in paragraph form, as are the six dependent variable items. After the subject reads the capsule description for all style variables, he responds on a Likert-type scale by indicating the degree to which the target person represents the particular style component.

In the short version of the CSM, the following components constitute the domain of communicator style.

Dominant. This attribute refers to the tendency to come on stong in most social situations. A person who takes charge of things when with others is dominant; a person who generally speaks very frequently in social situations is dominant.

Friendly. This attribute refers to a person who usually demonstrates kindly interest and goodwill toward others. This person is seldom hostile towards others and is usually regarded with high esteem by others. 
Attentive. This attribute refers to how alert a person is as a communicator. An attentive communicator tends to be encouraging to others, listening carefully to what they have to say. Such a person deliberately reacts in such a way that people know they are being listened to.

Relaxed. This attribute refers to how much at ease a communicator appears to be. A person who is not conscious of any nervous mannerisms in his speech is relaxed; a person who is calm and collected when talking is relaxed; a person whose rhythm or flow of speech is not affected by nervousness is relaxed.

Contentious. This attribute refers to a person who constantly quarrels and disputes with others. Such a person may be thought of as belligerent and the cause of much interpersonal unrest.

Dramatic. This attribute refers to how verbally alive a person is. A person whose speech tends to be very picturesque is dramatic; a person who frequently exaggerates to emphasize a point is dramatic; a person who vocally acts out what is being communicated is dramatic.

Animated. This attribute refers to how nonverbally active a person is as a communicator. A person who actively uses facial expressions and physical gestures is animated. A person whose eyes tend to reflect a great deal of what they are feeling is animated.

Open. This attribute refers to how self-disclosing a person is as a communicator. A person who readily reveals personal things or openly expresses feelings and emotions is an open communicator; when other people generally know the person's emotional state even if the person does not say anything, the person is open.

Impression-Leaving. This attribute refers to how affecting a person is as a communicator. What this person says as well as how he says it often leaves an impression. If people react to this person when they first meet and tend to remember him, this person is impression-leaving.

Communicator Image. This attribute refers to how good a communicator a person is. If a person finds it easy to talk on a one-to-one basis or in small groups with strangers, he has a good communicator image. A person who finds it easy to maintain a conversation with a member of the opposite sex has a good communicator image. 


\section{RESEARCH OBJECTIVES}

The following three independent studies were designed to investigate the relationship between communicator style and attraction. The objective in the first study was to measure the strength of relationship between the various communicator style variables and attraction. In the second study, the relative attractiveness of four distinct style types was assessed, as well as the predictive relationship between the individual style variables and attraction. Finally, in order to test the validity of the communicator style selfreport in regard to attraction, teachers were asked to evaluate students representing the four style types (selfreport) from their own perspective.

\section{STUDY 1}

\section{METHOD}

This study investigated whether an effect could be found between communicator style components and attraction. A measure of attraction (Byrne, 1971) was given simultaneously with the short version of the communicator style measure. Two conditions were studied.

\section{Conditions}

In the first condition, people were asked to respond to the questionnaire with their best friend in mind. "Best friend" was defined as the person they liked the best among their acquaintances.

In the second condition, people were asked to respond to the questionnaire with the person they liked least among their acquaintances in mind. In oral instructions, the subjects were told to: "Recall a set of your acquaintances. In your mind rank order these acquaintances in terms of liking. 
The person at the bottom of the ranking can be thought of as a "least liked friend"." A validity check showed that the manipulation in phrasing worked. The respective means for all attraction variables were significantly different beyond the $p<.01$ level.

\section{Subjects}

Ninty-seven volunteers from beginning communication classes at the University of Michigan filled out the questionnaires. For the first condition, 19 males and 26 females completed the measures. For the second condition, 24 males and 28 females completed the measures.

\section{Measures}

Two measures were used: (1) an attraction measure, and (2) a communicator style measure. Byrne's (1971) Interpersonal Judgment Scale was used to measure interpersonal liking. The instrument includes four filler items and two items measuring attraction-likability and desirability as a work partner. A seven-point Likert scale was used.

For the communicator style measure, seven independent variables (dominant, dramatic/animated, relaxed, open, attentive, impression-leaving) and one dependent variable (communicator image) were used. For this study, the dramatic and animated style variables were combined because of the conceptual closeness. Again, a seven-point Likert scale was used.

Finally, for each of the style variables, a question was asked concerning where the person should be put "ideally." For example, the subject was asked on the dominant variable to indicate where the target person would fall, and then the subject was asked to indicate where the target person should be "ideally." Using the modifier "ideally" provided an indication of how much change a subject would like to see for any particular style variable. 


\section{RESULTS}

Hotelling's $T^{2}$ statistic (Overall and Klett, 1972) showed that the communicator style variables in the mean vector differed significantly across the two conditions $\left(T^{2}=42.1\right.$; $F(6,90)=6.7 ; p<.01)$. This is an overall indicator that the style components are related to attraction components as operationalized in terms of "best liked" and "least liked" friend. The mean vectors for the style variables with the modifier "ideally" also differ across the two conditions $(T s 2 s=67.2 ; F(6,90)=10.6 ; p<.01)$.

\section{LIMITATIONS OF STUDY}

There are two problems with this study. First, the second condition, asking the subject to think of a "least liked friend," was awkward to identify and semantically difficult to analyze. Second, treating the communicator style variables additively only provides a crude indicator of the relationship between the style variables and the attraction variables.

\section{DISCUSSION}

The results from study 1 suggested a strong enough relationship that further exploratory studies were undertaken. Positive communicatory style attributes were strongly associated with people who are liked. They were seen as more dramatic, animated, relaxed, open, attentive, and as having a better communicator image. Two processes probably affected the evaluations. First, the person who is liked really does have a good style of communicating. Second, the person who is liked may adventitiously receive the benefit of an inflated rating.

The subjects did not want to change the style components of the "best liked friend." In fact, the ratings for the best friend did not change when the modifier "ideally" 
was included for each style component. However, the ratings for the "least liked friend" did change for some of the style components when the modifier "ideally" was included. They preferred the target person to be less dominant and impression-leaving and to be more attentive. In short, the person should signal a greater degree of other orientation.

This relationship was indicated further by the strong correlations between the attentiveness style variable and liking (.64), and the attentiveness style variable and desire to work with (.57). In other words, people are attracted to those who deliberately communicate in such a way that others know that they are being listened to.

\section{STUDY 2}

\section{METHOD}

The previous study showed a relationship between communicator style variables and attraction variables. But the conclusions are general and must be interpreted cautiously. In study 2, four types of communicator style were generated by combining specific subconstructs. Subjects were then asked to indicate which style types they were attracted to the most. This procedure eliminated the semantic problem of dealing with the phrase "least liked friend."

\section{Subjects}

Sixty-three volunteers from beginning communication classes at the University of Michigan filled out the questionnaire. 


\section{Generating Types of Communicator Style}

The dependent variable in this study was the type of communicator style. Four types of communicator style were generated from an earlier analysis of the long version of the communicator style measure, which sampled 1,086 subjects. A THAID (Morgan and Messenger, 1973) analysis was done on the data set. THAID is a form of regression analysis which employs a sequential binary split algorithm. "The primary idea behind the binary split algorithm is that the data be sequentially partitioned into two parts, determined by an independent variable's code, so as to optimize locally a criterion function for the dependent variable" (Morgan and Messenger, 1973: 9).

The THAID solution is shown in Figure 1. Communicator image is the dependent variable used in the analysis. The single best predictor among the nine independent variables is dominant. In the THAID model, 569 subjects saw them-

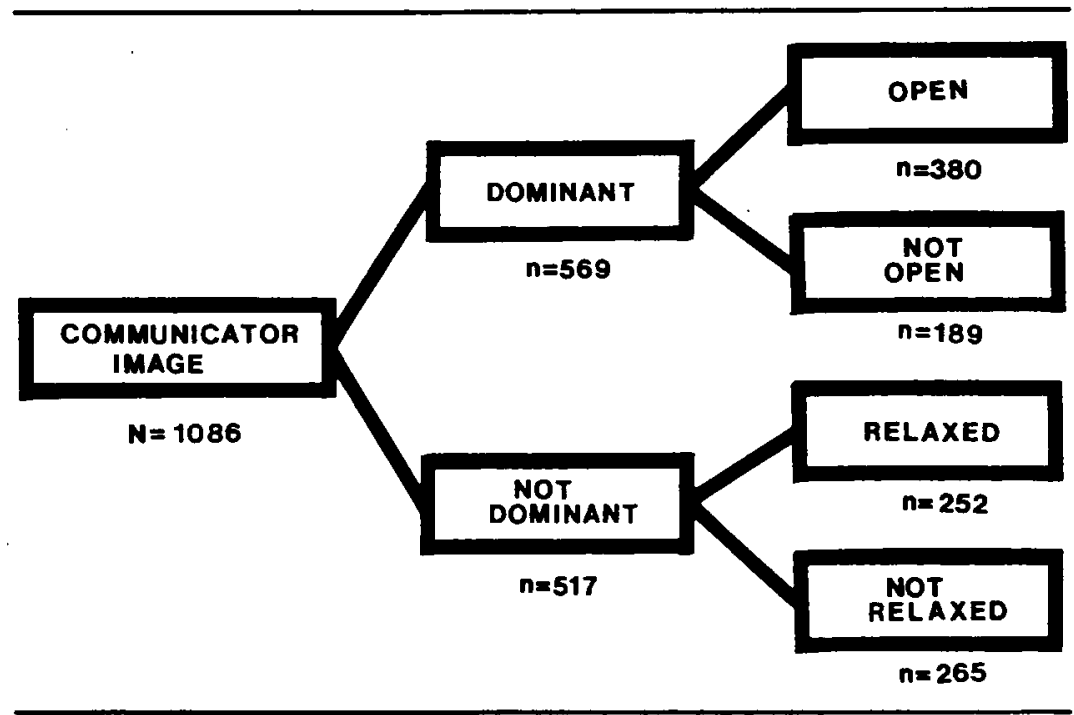

Figure 1: THAID Model for Communicator Style Variables 
selves as dominant, and 517 subjects saw themselves as not-dominant.

The THAID analysis next treats the dominant group as the dependent variable and the remaining eight style variables as predictors. Open emerged as the best predictor of the dominant group, with 380 of the 569 subjects seeing themselves as dominant and open. Similarly, 189 of the dominant group saw themselves as dominant and notopen.

In like manner, the not-dominant group is treated as the dependent variable, and the eight remaining style variables as predictors. Relaxed entered the model as the best predictor of the not-dominant variable-252 of the 517 subjects saw themselves as not-dominant and relaxed. The remaining 265 subjects viewed themselves as not-dominant and not-relaxed.

These four unique combinations of style variables were used to operationally define the types of communicator style in study 2-namely, a dominant/open style (type 1), a dominant/not-open style (type 2), a not-dominant/relaxed style (type 3), and a not-dominant/not-relaxed style (type 4). The commitment to this model means that particular style types are ignored, even though their inclusion would exhaust all combinations of the defining variables. In other words, the model indicates that the dominant/relaxed, dominant/not-relaxed, not-dominant/open, and the notdominant/not-open types are not sufficiently heterogeneous to warrant examination.

\section{Measures}

The same questionnaire used in study 1 was used in this study. Two small changes were made for Byrne's attraction measure and the short version of the communicator style measure. First, no items included the modifier "ideally." Second, a five-point scale, ranging from "much above average" to "much below average," was used for all items. 


\section{Procedure}

Each type of communicator style was printed in bold letters at the top of the measure. Four measures, representing each of the four styles, made up the questionnaire. The instructions asked the subjects to "think of a person whom you know best, representing the designated style of communication." The subjects were then asked to write the name of that person next to the target style. The filler, attraction, and communicator style variables were defined on the cover sheet of the questionnaire. The subjects were instructed to read the definitions carefully before naming and rating the target persons. All subjects completed the same scales for the four target persons.

\section{Validity Checks}

Three validity checks were built into the questionnaire. First, it was expected that for the dominant/open (type 1) and dominant/not-open (type 2) styles the means for the dominant item should be greater than the means for the dominant item for the not-dominant/relaxed (type 3) and not-dominant/not-relaxed (type 4) styles. The expectation was confirmed. The respective means were 4.5 and 2.4 $(t(252)=21.1, p<.01)$.

Second, type 1 and type 2 should differ for the open item. The expectation was confirmed. The mean for type 1 on the open item was 4.3; the mean for type 2 on the open item was $2.1(t(126)=15.4, p<.01)$.

Third, type 3 and type 4 should differ for the relaxed item. This expectation was also confirmed. The respective means were 4.0 and $2.1(t(126)=15.2, p<.01)$.

\section{RESULTS}

Two kinds of statistical analyses were used. First, central tendency differences were assessed among the four com- 
TABLE 1

Means for Communicator Image and Attraction across Style Types

\begin{tabular}{|c|c|c|c|c|}
\hline \multirow[b]{2}{*}{$\begin{array}{l}\text { Dependent } \\
\text { Variables }\end{array}$} & \multicolumn{4}{|c|}{ Types of Communicator Style } \\
\hline & $\begin{array}{l}\text { Type } 1 \\
\text { Dominant } \\
\text { Open }\end{array}$ & $\begin{array}{l}\text { Type } 2 \\
\text { Dominant/ } \\
\text { Not-Open }\end{array}$ & $\begin{array}{l}\text { Type } 3 \\
\text { Not Dominant/ } \\
\text { Relaxed }\end{array}$ & $\begin{array}{l}\text { Type } 4 \\
\text { Not Dominant } \\
\text { Not Relaxed }\end{array}$ \\
\hline $\begin{array}{l}\text { Communicator } \\
\text { Image }\end{array}$ & 4.2 & 3.5 & 3.2 & 2.7 \\
\hline Attraction & 4.1 & 3.9 & 3.4 & 3.2 \\
\hline
\end{tabular}

NOTE: The attraction variable is the average of two variables: (1) liking and (2) desire to work with.

municator style types. Second, a regression analysis was used to explore the predictive relationships between dependent and independent variables for all style types combined to obtain a general sense of the total data set.

\section{ANOVA for Attraction and Communicator Image}

An attraction score was constructed by averaging the liking and working with scores from Byrne's measure. A one-way ANOVA on the attraction score showed significant differences among style types $(F(3,248)=16.2, p<.01)$. Scheffe's method for post hoc comparisons $(p<.01)$ showed that type 1 was most attractive, and that type 2 was more attractive than type 3 and type 4 .

A similar pattern occurred in a one-way ANOVA for communicator image $(F(3,248)=26.2, p<.01)$. Type 1 had the best communicatory image $(p<.01)$, type 2 had a better communicator image than type $4(p<.05)$, and type 3 had a better communicator image than type $4(p<.01)$. Figure 2 shows the graphed means for both attraction and communicator image variables across style types. Table 1 reports the means across types. 


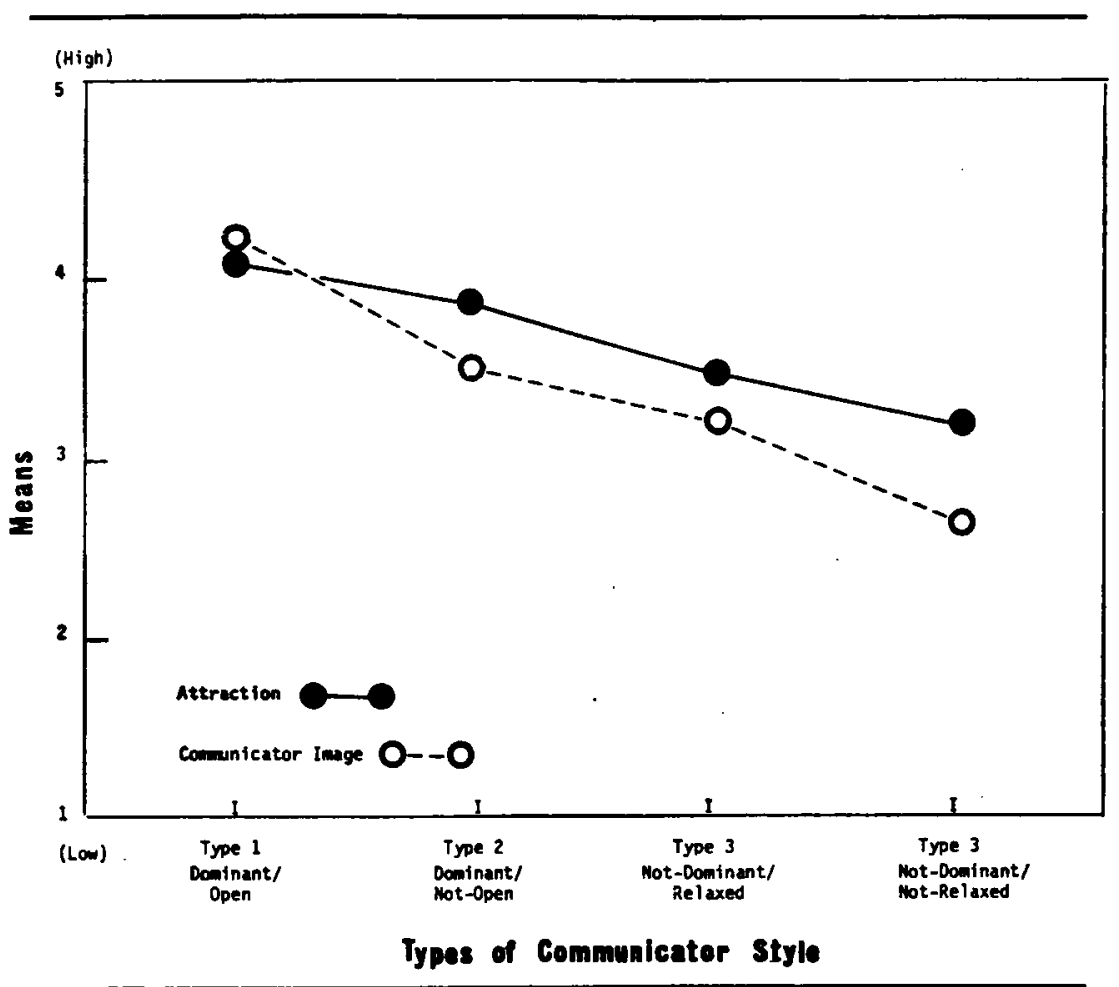

Figure 2: Mean Ratings for Attraction and Communicator Images across Style Typos

\section{Regression Analysis}

Multiple classification analysis (MCA; Andrews, Morgan, Sonquist, and Klem, 1973), a form of regression analysis, was employed to predict attraction from the ten style variables. This technique was chosen because it overcomes some of the traditional problems of multiple regression, such as correlated predictors, which cause difficulty in estimating the total variance explained. "A key feature of the MCA technique is its ability to show the effect of each predictor on the dependent variable both before and after taking into account the effects of all other variables" 
TABLE 2

Multiple Classification Analysis of Communicator Style Variables on Attraction

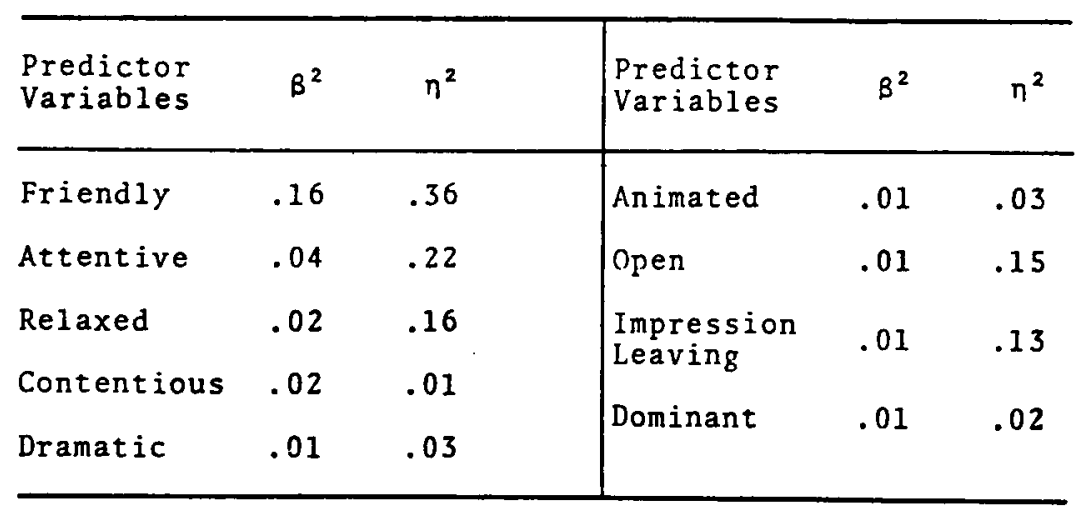

NOTES: $\beta^{2}$ indicates the approximate additive weights that each prodictor variable contributes.

$\eta^{2}$ indicates the percent of variance explained by the particular predictor veriable by itself. $R^{2}$ (unadjusted) equals .48 $R^{2}$ (odjusted) oquals .43.

(Andrews et al., 1973: 5) Table 2 reports the results of the MCA analysis.

Friendly emerged as the best overall style predictor of attraction. By itself, it explained $36 \%$ of the total variance. Attentive and relaxed were the next best predictors of attraction, respectively explaining $22 \%$ and $16 \%$ of the total variance. These percentages are variance explained by the particular predictor variables with the effects of all other variables removed; they are not weights in an additive regression model.

\section{Discussion}

The results of study 2 show that types of communicator style influence how attractive a person is perceived to be by a friend. The dominant/open style (type 1) was the most attractive style, while the not-dominant/not-relaxed style (type 4) was the least attractive. 
When viewed from a societal perspective, the findings are not surprising. The person who interacts in such a way that he takes charge of a conversation, comes on strong, and talks frequently demonstrates communicative competence. Furthermore, if the person interacts in such a way he makes himself vulnerable by being open, the person signals confidence and control. Such a style is rewarded in a competitive society which values hierarchies, sustains Horatio Alger myths, and rewards leadership.

The regression analysis indicates that the person who is perceived to be friendly, attentive, and relaxed in his style of communication is seen as more attractive than a person who does not interact this way. The dominant/open (type 1) communicator scored highest in each of these categories, although not significantly.

\section{STUDY 3}

\section{METHOD}

Study 3 represents an extension of study 2 . In study 2 the subjects specified target persons representing style types, and they evaluated the target persons. In study 3 , the target persons were determined by self-report. The subjects evaluated them without knowing about their styles.

\section{Target Persons}

Five hundred and eight students enrolled in beginning communication classes at the University of Michigan voluntarily filled out the long version (51 items) of the communicator style measure. Based on these scores, a pool representing the four style types from the THAID model was created.

To obtain relatively pure style types, a student had to score greater than one-half standard deviation from the 
mean in the appropriate direction for the defining variables. The criteria resulted in the following pool of target persons: (1) 67 subjects in the dominant/open style (2) 14 subjects in the dominant/not open style, (3) 11 subjects in the notdominant/relaxed style, and (4) 54 subjects in the notdominant/not-relaxed style. Eight subjects were drawn randomly for the respective pools for each style type.

\section{Subjects}

The subjects were 20 faculty and teaching assistants who had the above students in their classes.

\section{Measure}

A nine-item attraction measure was constructed for study 3 . The items were chosen in light of three attraction dimensions found in the literature: (1) liking and working together (Byrne, 1971), (2) personality (Griffitt, 1966, 1969; Byrne and Griffitt, 1969), and (3) physical features (Byrne, London, and Reeves, 1968; Byrne, Ervin, and Lambert, 1970; Stroebe, Insko, Thomson and Layton, 1971). Three items were selected for each factor (refer to Table 3 for the exact wording of each item). Four variables relating to communicator style also were included in the measure: (1) dominant, (2) open, (3) relaxed, and (4) communicator image. The variables served two purposes. First, they operated as a validity check for each of the styles. A dominant/open (type 1) style, for example, should be perceived as both dominant and open. Second, they camouflaged somewhat the true nature of the measure.

\section{Procedure}

Ten weeks after the initial pool of target persons had been generated, the subjects were asked to participate in a research project. The subjects were not told the nature of 
the study. They were given no indication that the target person had been selected in any special way. None of the teachers associated this study with the communicator style measure given out in their classes on the first day of the semester. None of the teachers guessed the research hypothesis when asked about it after the evaluations. In short, the teachers "blindly" evaluated the target persons.

At the top of each measure, the name of the respective target person who was in the teacher's class was printed. Under the name, an instruction requested that the teacher evaluate the target person along a 15-point scale for 13 items. Most of the teachers evaluated only one or two students.

\section{Validity Checks}

Table 3 shows the correlation coefficients for the attraction items. In a cluster analysis (Sneath and Sokal, 1973), the items grouped into the three posited factors. Thus, the attraction measure was structured as expected.

Also, the mean differences of dominant, open, and relaxed verified the validity of the THAID model. For the dominant variable, the means differed signficantly $(F(3,28)=$ $11.9, p<.01$ ). For the relaxed variable, the means differed significantly $(F(3,28)=4.0, p<.05)$. Finally, for the open variable, the means differed significantly $(F(3,28)=3.9$, $p<.05)$. In other words, the a priori structuring of the types matched the post hoc perception of the types.

\section{RESULTS}

Two nonparametric, Friedman tests were done on the data. This test was selected because of the small sample size in each condition. In the first test, the style types were compared across all nine attraction variables. The groups differed significantly $\left(\chi^{2}=17.9 p<.01\right)$. Table 4 reports the standardized means. 
TABLE 3

Correlation Coefficients of the Attraction Variables

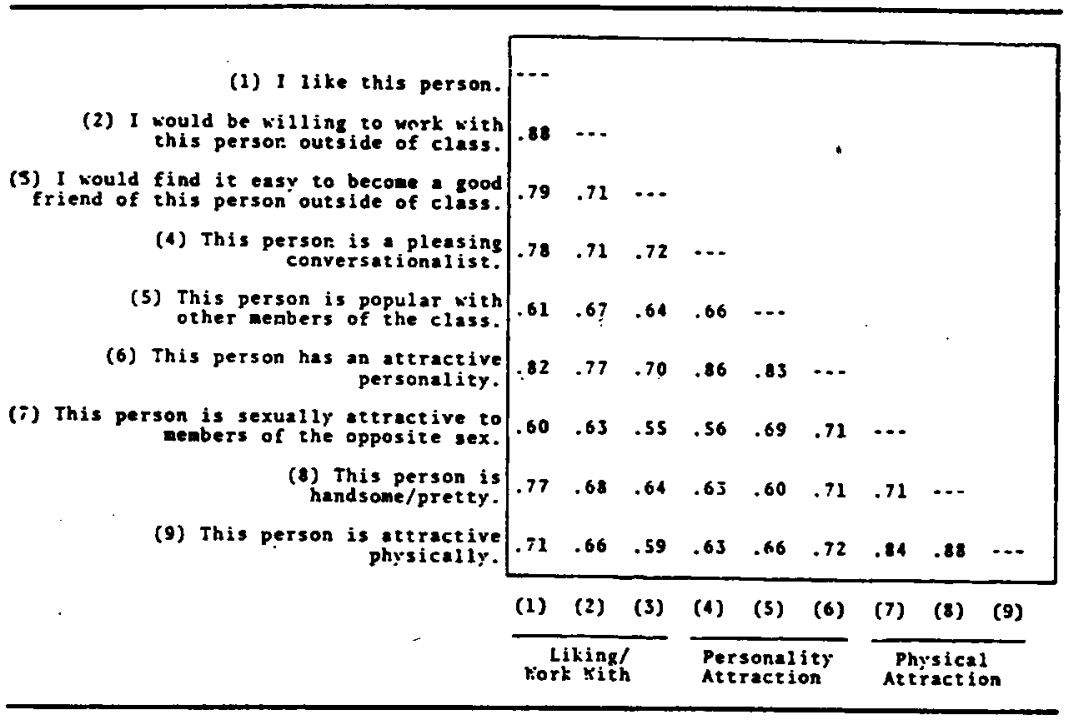

NOTE: In the cluster analysis, items (1), (2) and (3) grouped in the liking and working together factor; items (4), (5), and (6) grouped in the personality ettraction factor; items (7), (8), and (9) grouped in the physical attraction factor.

In the second test, the four style types were compared for the summed items for each attraction factor. The groups differed significantly. $\left(x^{2}=6.6, p<.05\right)$. Figure 3 shows the graphed scores.

\section{DISCUSSION}

The dominant/open style (type 1) was the most attractive in all categories. It was anticipated tht this style would be evaluated highly for two of the attraction factors. The surprising finding was the style type was evaluated also highly in the physical attractiveness factor. Two explanations are suggested.

First, the dominant/open style is sufficiently engaging that causes the perceiver to inflate the target person's attraction scores related to physical features-in effect, a carryover phenomenon because of the way one communicates. 
[276] COMMUNICATION RESEARCH / JULY 1977

TABLE 4

Means for Attraction Variables Across Style Types

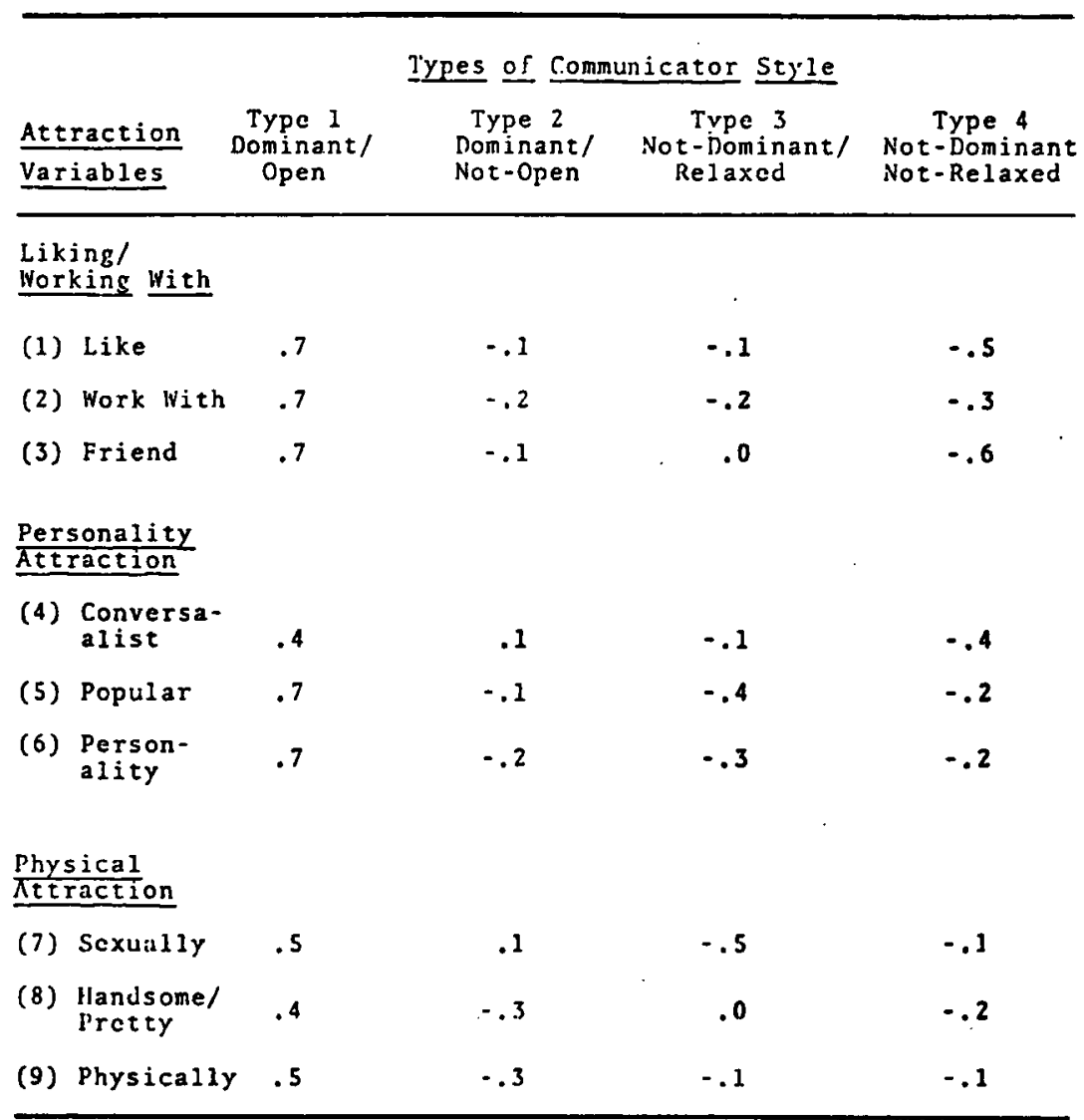

NOTES: For exact wording of the item, refor to table 3.

$\mathbf{N}=\mathbf{8}$ for each style type.

A second possibility is that people who are physically attractive receive strokes, feedback, and ego gratification from others such that they develop a style of communication that reflects confidence about themselves to the point where they manifest a dominant and open manner of communicating.

Type 1 is the only style that entails two positive variables. Being dominant seems to be a socially desirable behavior. Mortensen (1972) reports that dominance covaries strongly and positively with high self-esteem, self-acceptance, and 
Norton, Pettegrew / COMMUNICATOR STYLE [277]

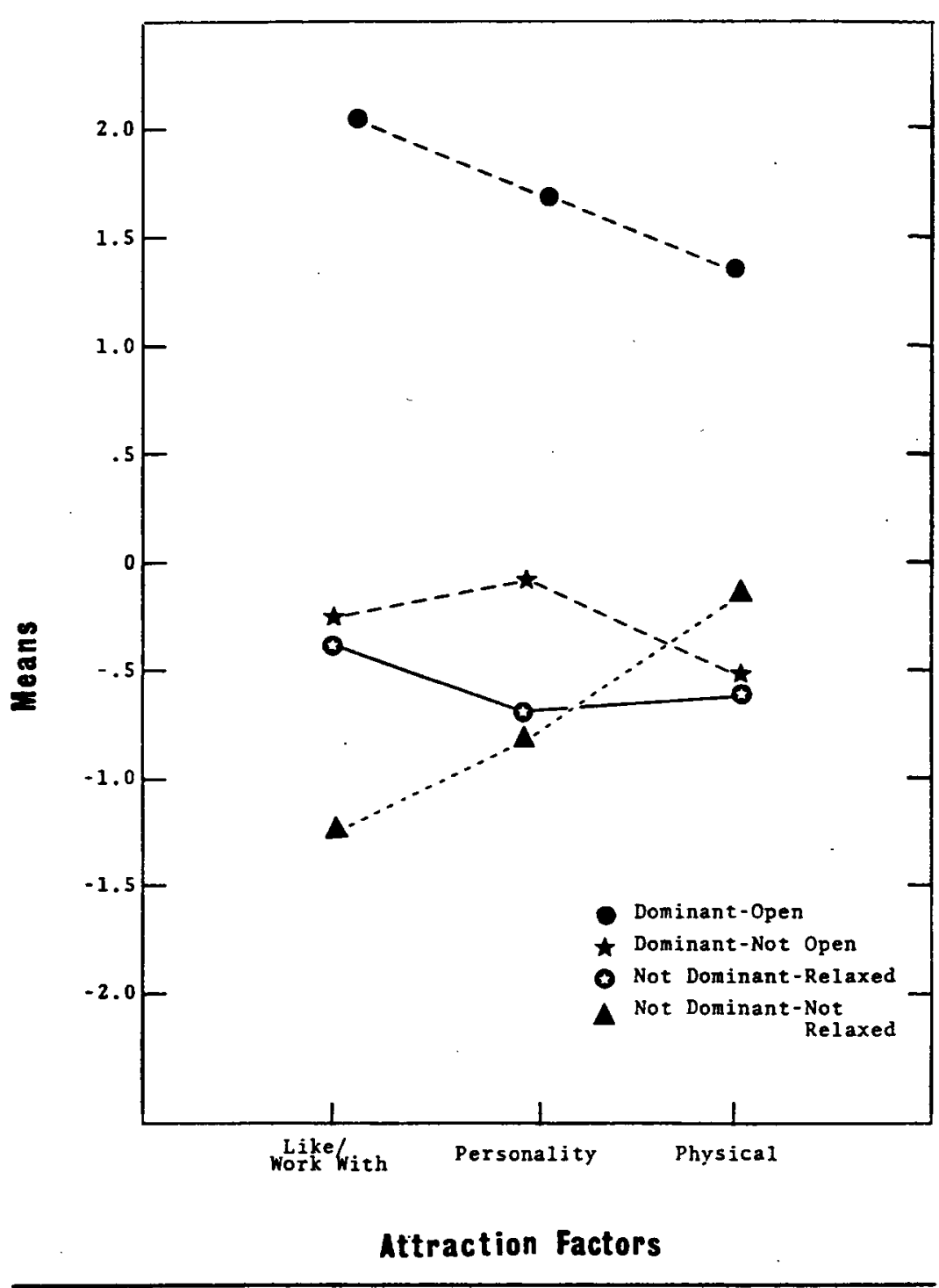

Figure 3: Ratings for Each Attraction Factor across Types

communication calmness. To the extent that dominant relates to these traits, it should be valued by others. An optimally dominant person should be liked because con- 
fidence, self-worth, and teleological behaviors are manifested.

In like manner, being open is a socially desirable behavior, connected with honesty, sincerity, and authenticity. However, there may be a point where a person could be too dominant or too open, reflecting a curvilinear relationship. For this study, the level of being dominant and open was appropriate, and not counterproductive.

A person who is dominant but not open (type 2) could be seen as interpersonally unreliable, undependable, untrustworthy, or insecure. This style of communicating may be debilitating in that ambiguity is not resolved for the other. If a person does not reveal things about himself, then he projects uncertainty about himself. Being closed, tightlipped, or silent could create an image of mistrust, possibly inferiority. Any one of these characteristics could affect the level of perceived attraction.

A person who is not dominant but relaxed (type 3) may manifest a rather bland manner of communicating. This person may prefer to follow rather than lead, to listen rather than talk, or to execute tasks rather than initiate them. The positive valence of relaxed could be misconstrued as passivity or social ineptitude.

A person who is not dominant and not relaxed has two negative factors against him. Being uptight, jittery, fidgety, agitated, excitable, tense, or anxious often causes the other person to react in the same way or to begin to dislike the person due to a feeling of psychological and social discomfort.

Again, the conclusion is that one's style of communicating is an important effect determinant of how he will be perceived in terms of attraction. The way one communicates not only directly influences whether one will be liked, chosen as a work partner, seen as popular, and seen as having a pleasing personality, but also affects adventitiously whether one will be seen as handsome or pretty. Furthermore, particular style types may be more suited for certain interactive situations such as those that demand competent and competitive social skills. 


\section{SUMMARY AND CONCLUSIONS}

From the results of the three studies presented in this research report, several conclusions emerge. First, certain communicator style variables appear to be strong covariates of attraction variables. This is intuitively appealing, since the way one communicates is such a pervasive part of one's interpersonal image. In study 1, subjects expressed satisfaction with the communicator style of their "best liked" firends, while indicating how their "least liked" friends might become better communicators. Specifically, they should become less dominant and impression-leaving and more attentive.

Second, certain communicator style types are both distinctive and stable enough to elicit evaluative differences in regard to their relative attractiveness and communicator images. In the second study, it was found that the dominant/open style (type 1) was the most attractive and had the best communicator image; the not-dominant/not-open style (type 4) was the least attractive and had the worst communicator image. These findings were replicated in study 3 in regard to three different indices of attractionphysical, personality, and liking working with. It is important to recognize that this effect was obtained from both students rating their acquaintances and teachers blindly rating their students.

Third, a particular domain of communicator style variables recurrently emerge as best predictors of attraction. They are attentive, friendly, and relaxed. These predictors point to specific areas of one's communicator style which can be manipulated to alleviate problems relating to a poor sense of self-worth, dysfunctional communication processes, and not being liked by others.

It is important to remember that these findings may be mediated by context, situation, and time. For example, style characteristics influencing attraction should vary depend-

ing upon a therapeutic (Pettegrew, 1977), academic (Norton, 1977), business, political, or religious context. In a like manner, they should also vary depending on whether 
the situation is loving, hating, playing, selling, lying, persuading, instructing, asserting, and so on. Finally, a time component is likely to influence style considerations. It is reasonable to hypothesize that as a person gets older his style of communication probably changes. A more adventuresome speculation is that communicator style varies with one's biorhythms-there may be cyclical periods in one's live in which one exhibits a more or less expressive style of communicating.

In conclusion, the three studies present strong evidence that communicator style is an effect determinant of attraction. It might have been somewhat surprising if the data had not supported this conclusion, since our work-a-day world so graphically reveals that is is often not what you say but how you say it that makes the difference. The task now becomes one of identifying optimal combinations of style variables that can predict consequents like effectiveness, empathy, conflict resolvability, emotional confortableness, and healthy personality, in addition to attraction. Such research must, of course, be done across situation, context, and time.

\section{REFERENCES}

ANDREWS, F. M., J. N. MORGAN, J. SONQUIST, and L. KLEM (1973) Multiple Classification Analysis: A Report on a Computer Program. Ann Arbor, MI: Institute for Social Research.

BALES, R. F. (1970) Personality and Interpersonal Behavior. New York: Holt, Rinehart, \&inston.

BREWER, R. F. and M. B. BREWER (1968) "Attraction and accuracy of perception in dyads." Journal of Personality and Social Psychology 25: 188-193.

BYRNE, D. (1971) The Attraction Paradigm. New York: Academic Press.

— (1969) "Attitudes and attraction." in L Berkowitz (ed.) Advances in Experimental Social Psychology. New York: Academic Press.

- and W. GRIFFITI (1973) “Interpersonal attraction." Annual Rev. of Psych. ology 11: 317-336.

(1969) "Similarity and awareness of similarity of personality characteristics as determinants of attraction." J. of Exper. Research in Personality 3: 179-186.

BYRNE, D., G. L. CLORE, and P. WORCHEL (1966) "The effect of economic similarity on interpersonal attraction." J. of Personality and Social Psychology 14: 220-224. 
BYRNE, D., C. R. ERVIN, and J. LAMBERT (1970) "Contunuity between the experimental study of attraction and real-life computer dating." J. of Personality and Social Psychology 16: 157-165.

BYRNE, D., O. LONDON, and K. REEVES (1968) "The Effects of Physical Attractiveness, Sex, and Attitude Similarity on Interpersonal Attraction." J. of Personality 36: 259-271.

BUSHARD, B. L. (1959) "Methodology of the study," in K. L. Artis (ed.) The Symptom as a Communication in Schizophrenia. New York: Grune Stratton.

DION, K. K. and E. BERSCHEID (1974) "Physical attractiveness and peer perception among children." Sociometry 37: 1-12.

and E. WALSTER (1972) "What is beautiful is good," J. of Personality and Social Psychology 24: 285-290.

GOSLIN, D. A. (1962) "Accuracy of social perception and social acceptance." Sociometry 25: 283-290.

GRIFFIT, W. (1969) "Personality similarity and self-concept as determinants of interpersonal attraction." J. of Social Psychology 78: 137-146.

(1966) "Interpersonal attraction as a function of self-concept and personality similarity-dissimilarity." J. of Personality and Social Psychology 4: $581-584$.

GULLAHORN, J. T. (1952) "Distance and friendship as factors in the gross interaction matrix." Sociometry 15: 123-134.

HAYES, D. and L. MELTZER (1972) "Interpersonal judgments based on talkativeness: fact or artifact." Sociometry 35: 338-361.

HOLSTEIN, C. M., J. M. GOLDSTEIN, and D. J. BEM (1971) "The importance of expressive behaviors, involvement, sex, and need-approval in inducing liking." J. of Exper. Psychology 7: 534-544.

IZARD. C. E. (1961) "Personality similarity and friendship." J. of Abnormal Psychology 61: 47-51.

KNOTT, P. D. and B. A. DROST (1965) "A measure of interpersonal dominance." Behavioral Research Methods and Instruments 1: 139-140.

LEARY, T. (1957) Interpersonal Diagnosis of Personality. New York: Ronald Press.

LEGINSKI, W. and R. IZZETT (1973) "Linguistic styles as indices for interpersonal distance." J. of Social Psychology 91: $291-304$.

LOWE, C. A. and J. W. GOLDSTEIN (1970) "Reciprocal liking and attributions of ability: mediating effects of perceived intent and personal involvement." J. of Personality and Social Psychology 16: 291-297.

MEHRABIAN. A. (1969) "Significance of posture and position in the communication of attitudes and status relationships." Psych. Bull. 71: 359-372.

- (1968) "Inference of attitudes from the posture, orientation, and distance of a communicator." J. of Consulting and Clinical Psychology 32: 296-308.

MIMS, P. R., J. J. HARNET, and R. W. NAY (1975) "Interpersonal attraction and help volunteering as a function of physical attractiveness." J. of Psychology 89: 125-131.

MORGAN, J. N. and R. C. MESSENGER (1973) THAID: A Sequential Analysis of Nominal Scale Dependent Variables. Ann Arbor, MI: Institute for Social Research.

MORTENSEN, D. (1972) "A report on the construct of speech intensity." Paper presented at the Speech Communication Association Convention, Chicago.

NEWCOMB, T. M. (1961) The Acquaintence Process. New York: Holt, Rinehart, \& Winston. 


\section{[282] COMMUNICATION RESEARCH / JULY 1977}

NORTON, R. W. (forthcoming) "Foundation of a communicator style construct." Human Communication.

(1977) "Communicator style and teacher effectiveness," in B. Ruben (ed.) Communication Yearbook I. New Brunswick, NJ: Transaction, Inc.

-_ and L. D. MILLER (1975) "Dyadic perception of communicator style." Communication Research 2: 50-76.

NORTON, R. W., L. S. PETTEGREW, and S. LAND (1975) "Communicator style correlates of attraction." Paper presented to the International Communication Association Convention, Chicago.

OVERALL, J. and C. KLETT (1972) Applied Multivariate Analysis. New York: McGraw Hill.

PETTEGREW, L S. (1977) "An investigation of therapeutic communicator style," in B. Ruben (ed.) Communication Yearbook I. New Brunswick, NJ: Transaction, Inc.

SHAPIRO. D. (1965) Neurotic Styles. New York: Basic Books.

SIEGEL, S. (1972) Nonparametric Statistics for the Behavioral Sciences. New York: McGraw-Hill.

SIMONSON, N. R. and S. BAHR (1974) "Self-disclosure by the profession paraprofessional therapist." J. of Consulting and Clinical Psychology 42: 359-363.

SNEATH, P. H. and R. R. SOKAL (1973) Numerical Taxonomy. San Francisco: W. H. Freeman.

STOEBE, W., C. A. INSKI, V. D. THOMPSON, and B. D. LAYTON (1971) "Effects of physical attractiveness. sex, and attitude similarity on interpersonal attraction." J. of Personality and Social Psychology 18: 77-91.

RUESCH. J. (1957) Disturbed Communication. New York: W. W. Norton.

WATZLAWICK, P., J. H. BEAVIN, and D. D. JACKSON (1967) Pragmatics of Human Communication. New York: W. W. Norton.

WEBLIN, J. (1962) "Communication and schizophrenic behavior." Family Process 1: 5-14.

WILLIAMS, E. (1975) "Medium or message: communiction medium as a determinant of interpersonal evaluation." Sociometry 38: 119-130.

Robert W. Norton received his Ph.D. from the University of Wisconsin before moving to the University of Michigan in 1972. He will be joining with the Department of Communication at Purdue University in September 1977.

Loyd S. Pettegrew is a doctoral student in the Department of Speech Communication and Theatre at the University of Michigan. 